\title{
THE UTILIZATION OF CARBOHYDRATES IN A CASE OF CHRONIC PENTOSURIA
}

\author{
By I. M. RABINOWITCH
}

(From the Department of Metabolism, Montreal General Hospital. Montreal, Canada)

(Received for publication April 23, 1926)

Recently an opportunity was afforded for a brief study of the carbohydrate and respiratory metabolism in a case of chronic pentosuria. Simultaneous blood sugar and respiratory quotient time curves were obtained following ingestion of glucose as described hereafter. As far as can be ascertained from the literature, such observations, in this rare disease, have not been recorded hitherto.

The subject, a male, aged 40, applied recently for a life assurance policy, and was rejected because sugar was found in his urine. Otherwise he was perfectly well and there were no signs suggesting diabetes mellitus. The applicant failed to mention the fact to the medical examiner, that he had had sugar in his urine since 1904 (for 22 years), at which time it was discovered accidentally, also during a life assurance examination. He also failed to present a letter (which he did to the author), given him by his physician at that time, showing that a diagnosis of pentosuria had been made.

Though alimentary pentosuria is not infrequently met with, chronic (essential, spontaneous) pentosuria is rare. Less than fifty cases are on record. Though relatively much has been written upon this condition, what is actually known is briefly and very clearly described in the recent edition of Garrod's classical monograph on "Inborn errors of metabolism" (1). It is therefore unnecessary to discuss in detail the various aspects of our knowledge of this disease. Only the essential features of clinical interest will be mentioned briefly.

The condition belongs to the group of "inborn" diseases, and is characterized by the presence of pentoses in the urine which bear no relation to the ingestion of these sugars. Of the forty-four cases recorded by Garrod, thirty-three were males. The youngest was a 
child five years old (Aron). Garrod points out that Alexander's case, a child of eighteen months of age, was probably of the "alimentary" type. Cammidge and Howard (2) record a case of a female, 75 years old. It tends to occur in several members of a family, but neither the parents nor offspring of such individuals are likely to be similarly affected-in this way differing from diabetes mellitus and renal glycosuria. The Hebrew race appears to be particularly liable. The condition is apparently harmless. Garrod mentions two individuals (Klercker) observed for ten years. Cammidge and Howard (2) record one who was treated for twenty-six years for diabetes. One subject reported by the late Theodore C. Janeway (3) in 1906 was recently met with by the writer. ${ }^{1}$ Having applied recently for life insurance, the company insisted upon a "sugar tolerance test," the results of which, however, indicate that his glucose metabolism is not perfectly normal. In the post absorptive state the blood sugar was 0.085 per cent. Following ingestion of one hundred grams of glucose, the blood sugar rose to 0.241 per cent at the end of thirty minutes, but returned to the original level in two and a half hours. In the case which is the subject of this report, the diagnosis, as just stated, was made twentytwo years ago (1904).

The amount of sugar excreted is usually small-about 5 gramsand is not affected by the ingestion of glucose yielding carbohydrates. Low protein and purin free diets have been noted to lessen excretion. Pentoses or pentose yielding foods ingested in the usual quantities, appear to be destroyed the same as in normal individuals. In the one case mentioned by Garrod (Blumenthal and Bial) in which an examination was made of the blood sugar, the latter was found to be normal. Cammidge and Howard (2) found excess urinary excretions of urobilin and amino acids in all of their seven cases, and therefore suggested defective liver function as an underlying cause.

\section{DIAGNOSIS}

Because arabinose does not reduce Fehling's solution as readily as glucose, and the amount of sugar is usually small, the reduction of this solution may be delayed-taking place some time after the second

${ }^{1}$ I am indebted to Dr. C. C. Birchard, Chief Medical Officer of the Sun Life Assurance Company of Canada, for having brought this case to my attention. 
heating, and then becoming apparent suddenly. This delayed reduction of Fehling's solution, frequently mentioned in text-books as being of diagnostic value, is not necessarily due to pentose, and is therefore unreliable for this purpose. Garrod points out that urines containing small traces of glucose may behave in the same way, and quotes Bial's observations that it may be observed when the urines have been kept for some time with addition of preservatives, such as toluene or chloroform. The pentose usually found in ckronic pentosuria is not fermentable by yeast and is optically inactive. Phenylhydrazine produces an osazone, with a melting point of $156^{\circ}$ to $160^{\circ} \mathrm{C}$., and a nitrogen content of 17.07 per cent. The special color reactions (red with phlorglucinol and green with orcin) are not obtained with glucose. Both of the colored substances are soluble in amyl alcohol, and the alcoholic solutions show characteristic spectroscopic bands. In the phlorglucinol test the bands lie between the Fraunhofer lines D and $\mathrm{E}$ (about $\lambda 5425$ to $\lambda 5750$ ) and in the orcin test between C and D ( $\lambda 5850$ to $\lambda 6150)$. Glycuronates give similar color reactions, but they may be eliminated from the urine by controlling the ingestion of substances yielding glycuronates. The compound glycuronates are optically active.

The physical signs in this case were negative and for brevity are omitted. A careful inquiry, with reference to the family history, failed to find any other member of the family similarly affected. The urine reduced Benedict's solution, did not ferment with yeast, and was optically inactive. Positive results were obtained both with the phlorglucinol, the old orcinol and Bial tests. The melting points of the osazone crystals obtained with phenylhydrazine on three different occasions were $158.5^{\circ}, 159^{\circ}, 158^{\circ}$, respectively. Quantitative determinations of the daily excretions were made by the sulphite-iodometric method described by Cammidge and Howard (2) and on three successive periods the results were as follows, 3.6, 2.5, 4.0 grams-an average of 3.3 grams per day. During the last period the diet was very high in carbohydrates. It will be noted this did not alter the amount of pentose excreted. Ten units of insulin had no effect upon the rate of excretion on the one day in which it was given. No excess excretion of urobilin was found in the urine by the method of Wallace and Diamond (4). The Van den Bergh reaction for bilirubin in the 
blood plasma was negative (direct and indirect). There was therefore no evidence in this case, as in those of Cammidge and Howard, of defective liver function.

In the post absorptive state, on February 18, 1926, the blood sugar was normal ( 0.078 per cent). One hundred grams of glucose were then given by mouth with the following blood sugar results:

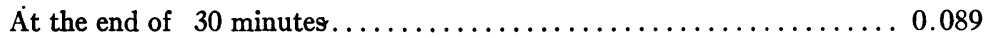

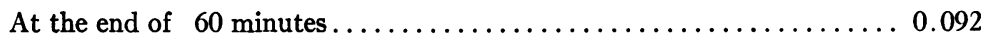

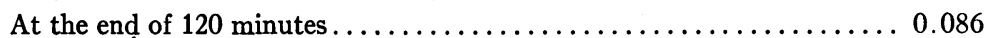

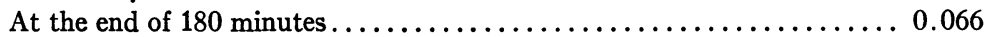

TABLE 1

Simultaneous respiratory exchange and blood sugar time curve data

\begin{tabular}{|c|c|c|c|c|c|c|c|c|c|c|c|}
\hline \multirow[b]{2}{*}{ Time } & \multicolumn{2}{|c|}{ Liters } & \multirow[b]{2}{*}{ 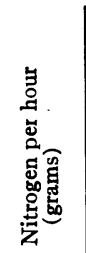 } & \multicolumn{2}{|c|}{ R.Q. } & \multirow{2}{*}{ 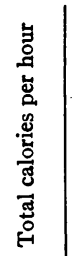 } & \multirow{2}{*}{ 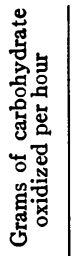 } & \multirow{2}{*}{ 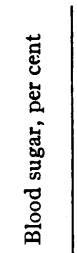 } & \multicolumn{3}{|c|}{$\begin{array}{l}\text { Percentage increase } \\
\text { above basal }\end{array}$} \\
\hline & 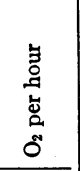 & 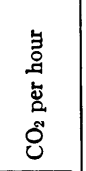 & & స్ & 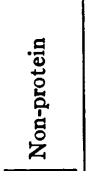 & & & & 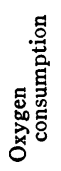 & 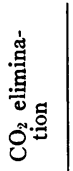 & 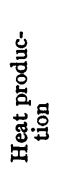 \\
\hline $\begin{array}{r}\mathrm{Ba} \\
30 \mathrm{~m}\end{array}$ & .68 & 4 & 0.402 & 0.822 & .824 & 66.1 & 5.93 & & & & \\
\hline & 14.82 & 11.57 & 0.430 & 0.781 & 0.776 & 70.8 & 4.0 & 0. & 8.3 & 2.9 & 7.1 \\
\hline & 15. & 12.73 & 0.444 & 0.849 & 0.858 & 72.9 & 8.66 & 0.113 & 9.6 & 13.2 & 10.2 \\
\hline 180 minutes & 13.38 & 11.72 & 0.400 & 0.876 & 0.891 & 65.6 & 9.29 & 0.068 & & 4.2 & \\
\hline
\end{tabular}

Sugar was found in the urines obtained at the end of each of the above periods. All specimens, with the possible exception of one, were, however, optically inactive, were not fermented by yeast, and gave a positive Bial reaction. In the one exception a small quantity of gas (equal to that from 0.25 per cent glucose) was found in the saccharometer, which did become smaller on the addition of sodium hydrate.

These observations alone suggested no disturbance in the ability of this individual to metabolize the ordinary carbohydrates. His dietary. habits are such that he takes the normal quantity of carbohydrates per day, and has no particular tendency to take pentose yielding fruits and vegetables. He returned for further observation on April 13, 1926, and at this time blood sugar and respiratory exchange time curves were obtained simultaneously. The procedures followed were the same as employed previously in this laboratory in a similar 
study of renal glycosuria (5), (6), and therefore need not be described here. The combined results are shown in table 1.

\section{DISCUSSION OF .RESULTS}

The blood sugar in the basal state was normal ( 0.080 per cent). Following the ingestion of 100 grams of glucose the maximum concentration ( 0.135 per cent) was noted at the end of one hour, and the original concentration was again reached before the end of the third hour. From these observations there was no indication of diminished sugar tolerance.

The total respiratory quotient in the basal state was 0.822 . A fall was noted at the end of the first hour. This phenomenon was previously (6) discussed and is compatible with the normal. The maximum increase $(0.054)$ was noted at the end of the third hour. The maximum percentage increments above the basal, of carbon dioxide production, oxygen consumption and heat production were 13.2, 9.6 and 10.2 respectively. The total amount of glucose oxidized during the three hour period was 21.99 grams or an average of 7.33 grams per hour.

All these values correspond to the normal. Confirmation, by modern methods, is therefore given to the general opinion held that in chronic pentosuria (unlike diabetes mellitus) the utilization of carbohydrates is unimpaired. There appears, therefore, to be no reason for either subjecting these individuals to restricted diets or classifying them as sub-standard insurance risks.

Grateful acknowledgment is due Miss Althea B. Frith and Miss Eleanor V. Bazin, who were responsible for all blood and respiratory air analyses.

\section{BIBLIOGRAPHY}

1. Garrod, A. E.: Inborn Errors of Metabolism, 2nd ed., 1923.

2. Cammidge, P. J., and Howard, H. A. H.: British Med. Jour., 1920, ii, 777. Seven Cases of Essential Pentosuria.

3. Janeway, T. C.: Amer. Jour. Med. Sc., 1906. Essential Pentosuria in Two Brothers.

4. Wallace, G. B., and Diamond, T. S.: Arch. Int. Med., 1925, xxxvi, 698. The Significance of Urobilin in Urine as a Test for Liver Function.

5. Finlay, F. G., and Rabinowitch, I. M.: Quart. Jour. Med., 1924, xvii, 260. Renal Glycosuria.

6. Rabinowitch, I. M.: Jour. Clin. Invest., 1925, ii, 143. Simultaneous Respiratory Exchange and Blood Sugar Time Curves. 